Revista Ibero-Americana de Ciências Ambientais

Ibero-American Journal of Environmental Sciences

Edição Especial do Congresso de Gestão Ambiental do Baixo Amazonas

(CONGABA) Ago 2018 - v.9 - n.6

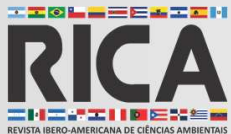

ISSN: 2179-6858

\title{
Ilha de calor urbana: diagnóstico como ferramenta de gestão ambiental urbana para a cidade de Santarém (PA)
}

Estudos sobre o clima urbano nem sempre estão presentes nos instrumentos legais de planejamento, limitando-se, muitas vezes, à climatologia regional. É o caso do Plano Diretor e de arborização de Santarém, que não leva em consideração dados meteorológicos. A hipótese central deste trabalho é que, com a expansão da malha urbana na região Santarém-Curuá-Una e Santarém-Alter do Chão, o gradiente de temperatura entre a área urbanizada e seus entornos tendem a aumentar, provocando a formação/intensificação de Ilhas de Calor Urbana e impactos no conforto ambiental da população. O objetivo desta pesquisa foi analisar as variações microclimáticas na escala espaço-temporal e a identificação de Ilhas de Calor Urbana - ICU, usando dados dados de superfície, em Santarém (PA). Esta cidade é a terceira maior do estado, tanto em dimensões territoriais, quanto em população. A temperatura e a umidade do ar foram medidas ao
longo de dois transectos, utilizando-se de termo-higrômetro digital, totalizando 31 pontos de coleta. As medições foram efetuadas nos dias 28 e 29 de janeiro de 2016 , entre $9 \mathrm{~h}$ e $21 \mathrm{~h}$. 0 estudo concluiu que Santarém apresenta elevadas temperaturas ao longo do dia e diferenças significativas de temperatura entre locais com diferentes concentrações de construções e pavimentação, ficando comprovada a formação de llhas de Calor. Também podemos destacar que o padrão de variação espacial de temperatura do ar e de umidade relativa evidencia que a cidade de Santarém já configura variação termo-higrométrica de centros urbanos, mesmo tendo proximidade com rios, igarapés e florestas. Na região de Santarém-Alter do Chão, a temperatura da área rural foi menor quando comparada à urbana, o que resulta em formação de llha de Calor Urbana, com intensidade forte e muito forte em todos os horários analisados. Isso implica em uma maior atenção de políticas públicas voltadas para esta área, visto que na Minuta do Projeto de Lei de Revisão do Plano Diretor de Santarém (2017) esta área é de expansão urbana. Recomenda-se que sejam desenolvidas políticas públicas de arborizacão e que as licenças para novos loteamentos e ordenamentos insiram áreas verdes em seus projetos, assim como políticas voltadas à manutenção e à remediação das áreas de proteção permanente ao longo dos igarapés e dos lagos inseridos nesta área. Há grandes chances de que a intensidade da llha de Calor Urbana aumente e impacte negativamente o conforto ambiental da população.

Palavras-chave: Clima Urbano; Amazônia; llhas de Calor.

\section{Urban heat island: diagnosis as an urban environmental management tool for the city of Santarém (PA)}

\begin{abstract}
Urban climate studies are not always present in legal planning instruments, often being limited to regional climatology. This is the case of the Master Plan and afforestation of Santarém which does not take into account weather data. The central hypothesis of this paper is that, with the expansion of the urban network in the Santarém-Curuá-Una and Santarém-Alter do Chão regions, the temperature gradient between the urbanized area and its surroundings tends to increase, causing the formation / intensification of islands. Urban Heat and impacts on the environmental comfort of the population. The objective of this research was to analyze the microclimatic variations in the spatiotemporal scale and the identification of Urban Heat Islands ICU, using surface data, in Santarém (PA). This city is the third largest in the state, both in territorial dimensions and population. Temperature and air humidity were measured along two transects using a digital thermo-hygrometer, totaling 31 collection points. The measurements were taken on January 28 and 29, 2016, between $9 \mathrm{~h}$ and $21 \mathrm{~h}$. The study concluded that Santarém has high temperatures throughout the day and significant temperature differences between sites with different concentrations of buildings and paving, thus proving the formation of Heat Islands. We can also highlight that the pattern of spatial variation of air temperature and relative humidity shows that the city of Santarém already configures thermo-hygrometric variation of urban centers, even having proximity to rivers, streams and forests. In the region of Santarém-Alter do Chão, the temperature of the rural area was lower when compared to urban, which resuls in the formation of Urban Heat lsand, with str results in the for erion (n) subdivision and ordinances include green areas in their projects, as well as policies aimed at the maintenance and remediation of permanent protection areas along the streams and lakes in this area. Chances are that the intensity of Urban Heat Island will increase and negatively impact the environmental comfort of the population.
\end{abstract}

Keywords: Urban climate; Amazon; Heat Islands.

Topic: Planejamento Urbano

Reviewed anonymously in the process of blind peer.

Leidiane Leão de Oliveira

Universidade Federal do Oeste do Pará, Brasil

http://lattes.cnpq.br/5016148560650320

leidianeoli@gmail.com

Clodoaldo de Sousa

Universidade Federal do Oeste do Pará, Brasil

http://lattes.cnpq.br/3237396487808561

clodoaldomaster@gmail.com

Naurinete de Jesus da Costa Barreto (iD

Universidade Federal do Rio Grande do Norte, Brasil

http://lattes.cnpq.br/8003316810277307

http://orcid.org/0000-0001-5167-6228

netebarreto@gmail.com

d

DOI: 10.6008/CBPC2179-6858.2018.006.0038
Received: 25/08/2018

Approved: $\mathbf{3 1 / 0 8 / 2 0 1 8}$

Gedinara Paiva dos Santos

Universidade Federal do Oeste do Pará, Brasil

http://lattes.cnpq.br/3313094495956562

narapaivasantos@gmail.com

Rodolfo Maduro Almeida (iD

Universidade Federal do Oeste do Pará, Brasil

http://lattes.cnpq.br/5710278151289710

http://orcid.org/0000-0003-4564-825X

rodolfomaduroalmeida@gmail.com
Referencing this:

SANTOS, F. C.; GUERREIRO, Q. L. M.; OLIVEIRA JÚNIOR, R. C.; BELDINI, T. P.; OLIVEIRA, D. R.. Trocas gasosas entre metano e óxido nitroso entre solo e atmosfera em diferentes tipos de cobertura na região oeste do Pará, Brasil. Revista Ibero Americana de Ciências Ambientais, v.9, n.6, p.428-443, 2018. DOI:

http://doi.org/10.6008/CBPC2179-6858.2018.006.0038 


\section{INTRODUÇÃO}

No, Brasil o crescimento demográfico em áreas urbanas é agravado, sobretudo, pela falta de planejamento, fato que compromete a qualidade ambiental nas cidades. A expansão das áreas urbanas é frequentemente associada a mudanças no clima local (OLIVEIRA et al., 2011). Entre os impactos resultantes da ocupação desordenada do solo em área urbana, podemos citar a modificação das condições iniciais do clima por meio da alteração do balanço energético no sistema superfície-atmosfera, em escala mesoclimática.

Assim como as alterações na cobertura natural do solo e o incremento de massa edificada, entre outros fatores, criam um clima peculiar denominado "clima urbano" (GARTLAND, 2010). O clima urbano é um fator que contribui para a formação do fenômeno llha de Calor Urbana - ICU que é definida como o aumento da temperatura da superfície e do ar sobre uma área urbana, em relação às áreas rurais ou suburbanas vizinhas (ARYA, 2001).

Durante o dia, nas áreas rurais, a energia solar absorvida próxima do solo evapora água da vegetação e do solo. Assim, enquanto há ganho líquido de energia solar, isto é compensado com alguns graus pelo resfriamento evaporativo (LEAL, 2012). Em cidades, onde há menos vegetação, as construções e pavimentação absorvem a maior parte da energia solar que atinge a superfície. Devido à menor capacidade de infiltração do solo, a perda de água por escoamento superficial é maior pois os pavimentos na maioria não são porosos.

Assim, o resfriamento evaporativo é menor, contribuindo para as altas temperaturas (KING et al., 2011). As cidades têm uma atmosfera mais instável o que ocasiona diminuição na velocidade do vento em relação ao campo. Assim, a tendência do ar, sob condições atmosféricas estáveis, é circular do campo: menos quente, alta pressão - em direção ao centro; mais quente, baixa pressão (AMORIM, 2005; UCHÔA, 2011).

A diminuição das áreas de florestas devido ao crescimento populacional e demanda de espaços para construção e moradias, fato ocorrido principalmente nos grandes centros urbanos, faz aumentar significativamente a irradiação de calor para a atmosfera em comparação com as zonas periféricas ou rurais, onde a vegetação é mais abundante (TEZA, 2005). Nota-se os diferentes padrões de refletividade ou albedos, são altamente dependentes dos materiais empregados na construção civil. Percebe-se que a quantidade de radiação absorvida e o calor emitido por uma superfície é diretamente associado ao albedo.

O aquecimento das áreas urbanas é causado principalmente pelo calor antropogênico de veículos, indústrias, ar condicionado e outras fontes de calor, e devido ao calor armazenado e irradiado pelas enormes e complexas estruturas urbanas, cuja rugosidade reduz a remoção do calor convectivo, (MEMON, et al., 2008; SOUZA et al., 2012).

Estudo que aborda as condições de conforto térmico em outras cidades com mesmo porte que Santarém, verificaram devido à expansão urbanas, essas cidades já apresentam sensível diferença entre o meio urbano e o rural. Um exemplo é a cidade de Cajuri (MG), onde foi observado uma considerável variação de temperatura entre a área mais adensada e a zona rural, varia de $3,7^{\circ} \mathrm{C}$ a $4,8^{\circ} \mathrm{C}$, entre $9 \mathrm{~h}$ e $15 \mathrm{~h}$; já às $21 \mathrm{~h}$, a variação oscila próximo a $2,1^{\circ} \mathrm{C}$. (FIALHO, 2016). Outra cidade também estudada recentemente é Palmas (TO); 
lá, foi observado que a temperatura do ar no eixo central da cidade apresentou-se mais elevada, proporcionando elementos com alta densidade de ocupação e pouca presença de massa arbórea, implicando em um estresse térmico muito maior (FREITAS, 2016).

Diniz Júnior (2013) concluiu que a vegetação, entre outros benefícios, influência nos dois mecanismos principais para a redução da temperatura do ar: o processo de evapotranspiração, que converte a energia solar em água evaporada ao invés de aumentar a temperatura do ambiente; e o sombreamento, que mantém as superfícies mais frescas, reduzindo a emissão de calor. A formação de ilhas de calor urbana é um dos fenômenos climáticos mais característicos do mau planejamento urbano (UCHÔA, 2011).

Os estudos sobre clima urbano nem sempre estão presentes nos instrumentos legais de planejamento, limitando-se muitas vezes a climatologia regional. Como exemplo, Plano Diretor de Santarém e Minuta do Projeto de Lei de Revisão do Plano Diretor de Santarém não levam em consideração dados meteorológicos, limita-se a valores médios, a condições climáticas regionais, tratando de forma igual as áreas verdes, as mais densamente urbanizadas e as menos habitadas, não levando em consideração a especificidade de cada área da cidade (SILVA, 2016).

A hipótese levantada neste estudo, compreende que com a expansão da malha urbana na região Santarém - Curuá-Una e Santarém-Alter do Chão, o gradiente de temperatura entre a área urbanizada e seus entornos tende a aumentar provocando a formação/intensificação de Ilha de Calor Urbana e impactos no conforto ambiental da população.

A cidade de Santarém (PA) apresenta acelerado crescimento urbano. Tendo em vista que tal crescimento urbano é um dos principais fatores que contribuem para as alterações do microclima. Assim, é necessário estudos que investiguem o clima urbano e que estes sirvam de instrumentos para o planejamento, por exemplo, de áreas verdes em pontos estratégicos da cidade. Deste modo o presente trabalho teve como objetivo principal analisar as variações microclimáticas nas escalas espaço-temporal e identificação de Ilha de Calor Urbana - ICU em Santarém (PA) para os dias 28 e 29 de janeiro de 2016. Este estudo é de extrema importância, pois busca gerar subsídios para um diagnóstico do clima urbano de Santarém, em prol de um melhor desenvolvimento urbano e qualidade ambiental.

\section{MATERIAL E MÉTODOS}

\section{Área de estudo}

O estudo foi desenvolvido na cidade de Santarém. Localizada na Amazônia Paraense, na confluência dos rios Amazonas e Tapajós, possui uma área de 22.887,080 km², sendo que 77 km² estão em perímetro urbano, e está compreendida entre as coordenadas $54^{\circ} 39^{\prime} 00^{\prime \prime} \mathrm{W}$ e $54^{\circ} 48^{\prime} 00^{\prime \prime} \mathrm{W}$ de longitude oeste e $2^{\circ} 55^{\prime} 44^{\prime \prime} \mathrm{S}$ e $2^{\circ} 31^{\prime} 44^{\prime \prime} \mathrm{S}$ de latitude, conforme delimita (figura 01). A altitude média do perímetro urbano é de 36 metros, e possui uma população estimada para o ano de 2017 de 296.302 habitantes (IBGE, 2012). A cidade apresenta o clima Amazônico equatorial, quente e úmido (AGUIAR, 1995), com duas estações bem definidas, sendo o período chuvoso, que abrange os meses de dezembro a maio, e período seco, que abrange os meses de junho a novembro. 


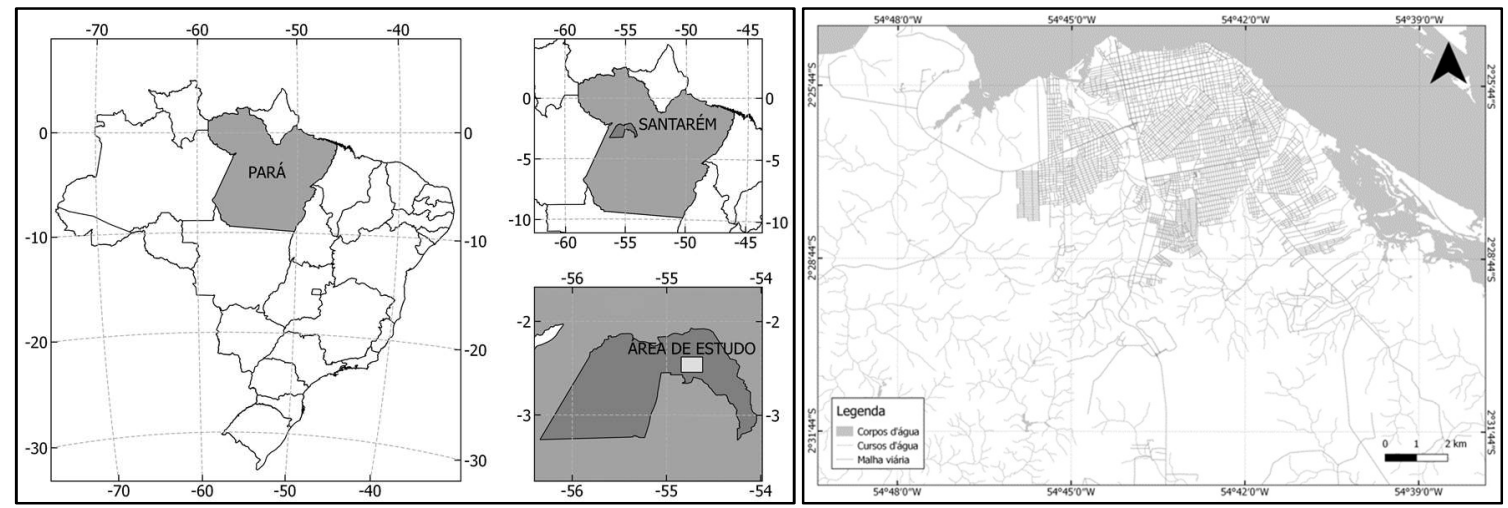

Figura 1: Localização da cidade de Santarém (PA).

\section{Transectos}

Para a coleta dos dados termo-higrométricos, foram traçados dois transectos, que partiram da zona rural rumo a zona urbana, em dois sentidos, Norte-Sul (Sanatrém-Curuá-Una) e Leste-Oeste (Santarém-Alter do Chão). O transecto Norte-Sul contemplou em seu maior percurso a rodovia PA-370 (Santarém Hidrelétrica de Curuá-una). O transecto Leste-Oeste contemplou em sua maior parte os percursos ao longo das rodovias estaduais PA-453 (Rodovia Engenheiro Fernando Guilhon) e PA-457 (Rodovia Everaldo Martins) (Santarém-Alter do Chão). Ao longo dos transectos foram definidos pontos de coleta dos dados termohigrométricos, separados a cerca de um quilômetro de distância um do outro, onde foram extraídas as coordenadas geográficas com o uso um aparelho de Sistema Global de Posicionamento por Satélite Artificial (GPS) da marca Garmin.

O sentido dos pontos de coleta foi de sul para norte e de oeste para leste, onde os pontos iniciais foram localizados nas zonas rurais, a cerca de $14 \mathrm{~km}$ de distância do centro da cidade e os pontos finais no centro da cidade (figura 02). Os dois percursos realizados privilegiaram a passagem por áreas com diferentes usos e ocupações do solo.

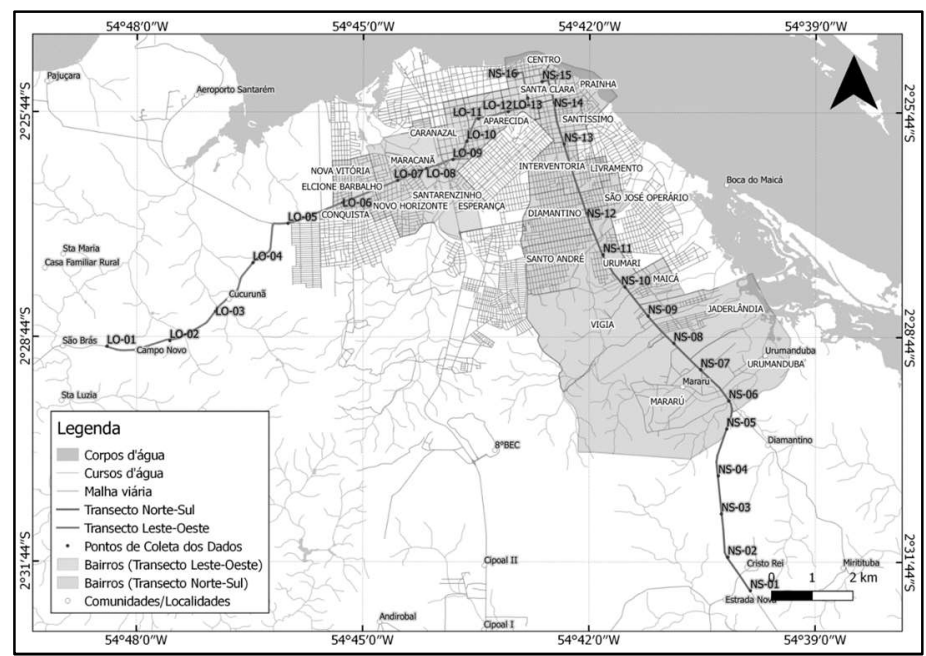

Figura 2: Transectos Norte-Sul (Santarém-Curuá-Una) e Leste-Oeste (Santarém-Alter do Chão).

O transecto Norte-Sul, no sentido da zona rural para o centro da cidade, passou pelas comunidades rurais Estrada Nova e Cristo Rei, e pelos bairros Mararu, Urumanduba, Vigia, Jaderlândia, Maicá, Urumari, Santo André, Diamantino, São José Operário, Livramento, Interventoria, Santíssimo, Prainha, Santa Clara e 
Centro. O transecto Leste-Oeste, no sentido da zona rural para o centro da cidade, passou pelas comunidades rurais Campo Novo e Cucurunã, e pelos bairros Conquista, Elcione Barbalho, Novo Horizonte, Nova Vitória, Santarenzinho, Maracanã, Esperança, Caranazal, Aparecida, Santa Clara e Centro. A figura 2 indica os transectos, comunidades e bairros por onde passaram.

\section{Coleta dos Dados}

As coletas dos dados in situ foram realizadas com o auxílio de um termohigrômetro digital portátil da marca Extech, (figura 3), nos dias 28 de janeiro de 2016 para o transecto Leste-Oeste e 29 de janeiro de 2016 para o transecto Norte-Sul. Os dias estabelecidos estavam em condições de tempo atmosférico ideal, ou seja, céu claro e ventos fracos, assim como sugeridos por Oke (1982).

Em cada ponto foram realizadas cinco coletas, respectivamente, nos horários de 09h, 12h, 15h, 18h e $21 \mathrm{~h}$, com o tempo de um minuto para a estabilização do aparelho em cada coleta. 0 tempo total entre o início e o fim da coleta durou cerca de 50 minutos. De acordo com Araújo et al. (2010), o tempo de duração de coletas em transectos não pode ultrapassar uma hora.

\section{Detecção de Ilhas de Calor Urbana através de dados de superfície}

Para a determinação das ilhas de calor foram utilizadas as temperaturas da zona rural e urbana em cada um dos horários de coleta, sendo assim, os pontos inicial e final de cada coleta, representam as temperaturas rural e urbana em cada um dos transectos, a temperatura no ponto um foi a rural e a temperatura no ponto foi a urbana. Os dados dos pontos extremos devem indicar se ocorre a formação da Ilha de Calor e qual a sua intensidade, obedecendo o método utilizado por Gomez e Garcia (2003), que agrupa a magnitude em função da intensidade (tabela 1).

Tabela 01: Classificação da ilha de calor conforme sua magnitude em função da intensidade de acordo com Gomez; Garcia (2003)

\begin{tabular}{|c|c|}
\hline Diferença de Temperatura & Intensidade da Ilha de Calor \\
\hline Entre 0 a $2^{\circ} \mathrm{C}$ & FRACA \\
\hline Entre 2 a $4{ }^{\circ} \mathrm{C}$ & MODERADA \\
\hline Entre 4 a $6^{\circ} \mathrm{C}$ & FORTE \\
\hline Maior que $6^{\circ} \mathrm{C}$ & MUITO FORTE \\
\hline
\end{tabular}

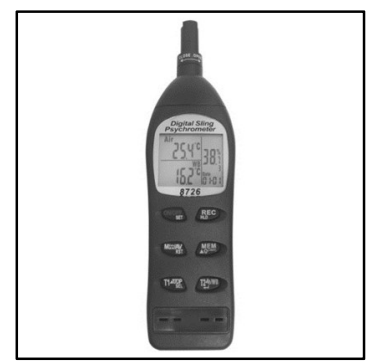

Figura 3: Piscicrômetro Extech utilizado na coleta de dados deste estudo.

\section{Conforto Térmico}

Para aferição do conforto térmico foi levada em consideração todos os pontos amostrais, utilizando a média diária de temperatura e umidade do ar de cada um dos pontos em ambos os transectos. O conforto 
térmico foi avaliado através do Índice de Temperatura Umidade (ITU), por apresentar boa resposta para a região tropical. $O$ objetivo deste é expressar o grau de desconforto sentido por um ser humano em atividade, sem considerar as condições de radiação e ventilação. O método é descrito pela expressão, abaixo: ITU = [Tar - (1-0,01 . UR) . (Tar-14,5)], onde Tar é a temperatura do $\operatorname{ar}\left({ }^{\circ} \mathrm{C}\right)$ e UR é a umidade relativa do ar (\%).

Tabela 2: Sensação de conforto térmico do corpo relacionado com o Índice de Temperatura e Umidade.

\begin{tabular}{|c|c|}
\hline FAIXA (ITU) $\left({ }^{\circ} \mathbf{C}\right)$ & DESCONFORTO \\
\hline 29 & Estresse \\
\hline $27-29$ & Muito Desconfortável \\
\hline $24-27$ & Desconfortável \\
\hline $21-24$ & Confortável \\
\hline
\end{tabular}

\section{Tratamento dos dados}

Os resultados das medições de temperatura e umidade foram submetidos à testes estatísticos no programa R Core Team. Os resultados devem indicar a ocorrência da variação termo-higrométrica ao longo dos dois transectos, além de serem submetidos à análise de variância, com objetivo de verificar a relação entre os horários das medições e os pontos, os resultados foram comparados pelo teste Tukey, a nível de 5\% de significância. Após obter os resultados da variação em cada transecto, os dois foram comparados entre si para verificar se existe variação entre os dois. Os valores das temperaturas rural e urbana foram tabulados e o resultado da diferença deve indicar se há formação da ilha de calor urbana, bem como sua intensidade, bem como os dados para a aferição do conforto térmico nos pontos ao longo dos transectos, irão indicar a situação do conforto térmico na cidade.

\section{RESULTADOS}

\section{Variação termo-higrométrica temporal}

A variação da temperatura e umidade do ar ocorreu para os dois transectos em escala temporal. As temperaturas horárias apresentam variação características da região equatorial, com aumento gradativo das primeiras horas do dia, até valores máximos às $15 \mathrm{~h}$, seguindo de uma diminuição a partir desse horário, atingindo menores valores às 21 horas. Os resultados das variações de temperatura e umidade encontradas no transecto Norte-Sul são apresentados abaixo (figura 4).
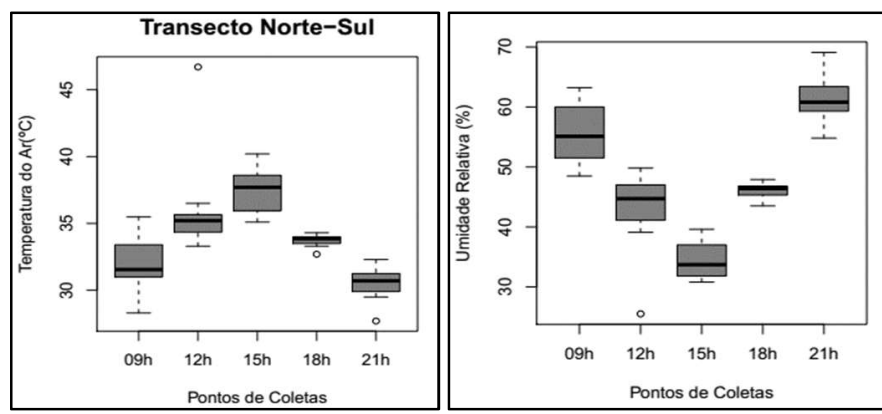

Figura 4: Temperatura e umidade nos diferentes horários no transecto Norte - Sul (Santarém-Curuá-Una).

A variação termo-higrométrica espacial no transecto Norte - Sul no horário das $15 \mathrm{~h}$ alcançou o os valores mais elevados de temperaturas chegando a atingir $40,2^{\circ} \mathrm{C}$. Pode ser observado que, às $9 \mathrm{~h}, \mathrm{a}$ 
temperatura variou entre 22,5 a $36,5^{\circ} \mathrm{C}$, e às 15 horas a variação ocorreu entre 35,8 e $38,2^{\circ} \mathrm{C}$. Sendo assim, a temperatura do ar aumentou com o passar do tempo, atingindo os valores máximos às 15 horas. Depois desse horário, a temperatura começa a diminuir até atingir valores mínimos no horário às 21 horas, variando entre $29,7^{\circ}$ e $30,9^{\circ} \mathrm{C}$.

A umidade relativa do ar apresenta variação inversa à temperatura, com valores de maior expressividade encontrados no início e no fim do dia, pois com o aumento da temperatura a água tende a evaporar rapidamente favorecendo a queda na umidade, sendo assim a umidade apresentou maiores valores nos horários de 9 horas $(60,8 \%)$ e 21 horas (63\%) e menores valores no horário das 15 horas (31\%). Abaixo, são apresentados os resultados das variações termo-higrométricas encontradas no transecto Leste-Oeste (figura 5).
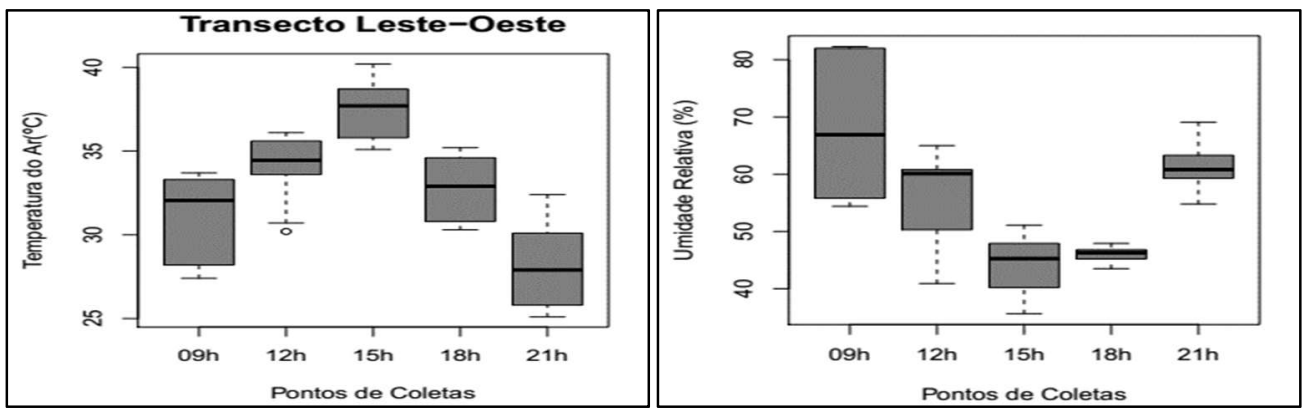

Figura 5: Temperatura e umidade nos diferentes horários no transecto Leste-Oeste (Santarém - Alter do Chão).

Assim, como no transecto Norte-Sul a variação termo-higrométrica espacial no transecto Leste Oeste apresenta variação horária, sendo que às $15 \mathrm{~h}$ atingiu os valores mais elevados de temperaturas chegando a atingir $40,2^{\circ} \mathrm{C}$. No horário de $9 \mathrm{~h}$ a variação da temperatura foi de 27 a $34,6^{\circ} \mathrm{C}$, passando a aumentar até às 15 horas onde a variação foi de 35,1 a $38,7^{\circ} \mathrm{C}$, esse foi o horário de maior temperatura, com diminuição gradativa até atingir valores mínimos no horário de $21 \mathrm{~h}$, variando de 25,4 a $29,9^{\circ} \mathrm{C}$.

A umidade relativa do ar acompanha a variação da temperatura, porém, no sentido inverso, já que quanto maior os valores de temperatura, menores os valores de umidade relativa do ar registrados nos horários e pontos amostrados, quando menor a temperatura maior foi a umidade relativa do ar, sendo assim, a umidade apresentou maiores valores nos horários: 9 horas (83\%) e 21 horas (68\%) e menores valores no horário das 15 horas (38,5\%).

\section{Variação termo-higrométrica espacial}

Foram evidenciadas temperaturas menores em áreas com maior cobertura vegetal, ou seja, do início da coleta as temperaturas apresentam um aumento da zona rural até a zona urbana, A variação da temperatura e umidade relativa do ar varia de acordo com os pontos específicos como amostrados neste estudo (figuras 6 e 7).

A variação da temperatura e umidade relativa do ar ocorreu no transecto Norte -Sul, na qual, apresenta uma flutuação nos valores. Os pontos que apresentaram menores flutuações de temperatura do ar foram os pontos um (P01) e dezesseis (P16). O ponto um (P01) apresentou pouca variação, no qual temperatura do ar variou de 32,2 a $34,1^{\circ} \mathrm{C}$ e o ponto dezesseis $(\mathrm{P} 16)$ com variação de 34,4 a $36,3^{\circ} \mathrm{C}$. Dois 
pontos que apresentaram maiores amplitudes de temperatura do ar, o ponto cinco (P05) que variou de 28,3 a $35,5^{\circ} \mathrm{C}$ e o ponto nove (P09) que variou de 31,3 a $38,7^{\circ} \mathrm{C}$, essa diferença de temperatura pode estar associada ao tipo de uso do solo, a presença de vegetação, ao fluxo de veículos, bem como as atividades desenvolvidas no entorno ou com a altitude do local.
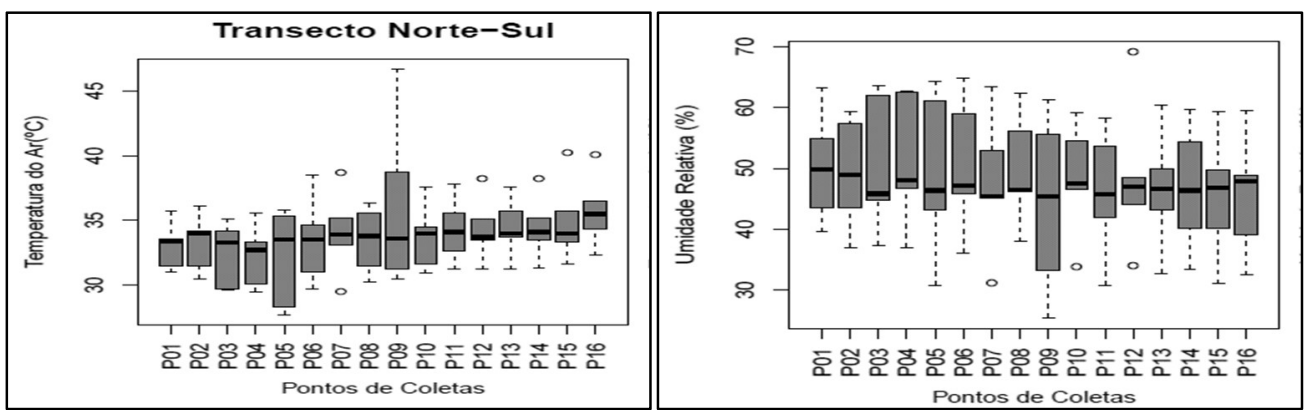

Figura 6: Temperatura e umidade relativa do ar nos diferentes pontos no transecto e Norte - Sul (Santarém-CuruáUna).

A umidade relativa variou de acordo com a temperatura do ar, sendo que os menores valores foram identificados no ponto nove (P09), no qual, variou de 32 a 53\% e os maiores valores no ponto quatro (P04), variou de 42 a 60\%, isso mostra que a umidade diminui de acordo com a aproximação do centro da cidade, isso pode ser explicado pelo fato de os materiais empregados na construção das casas e na pavimentação das ruas serem de fácil absorção de calor, o que faz com que a umidade seja rapidamente perdida para atmosfera superior, proporcionando assim, ar seco e quente no centro da cidade.

A variação termohigrométrica para o transecto Leste-Oeste apresenta variações com aumento progressivo da temperatura da área rural ponto um (P01) para o centro da cidade ponto quatorze (P 14), sem apresentar pontos fora do padrão de aumento, ou flutuações significativas nos valores de temperatura. A umidade relativa do ar, ao contrário da temperatura, apresenta um decréscimo no sentido área urbana. Os valores mais altos foram registrados na zona rural, os valores mais baixos na área urbana.

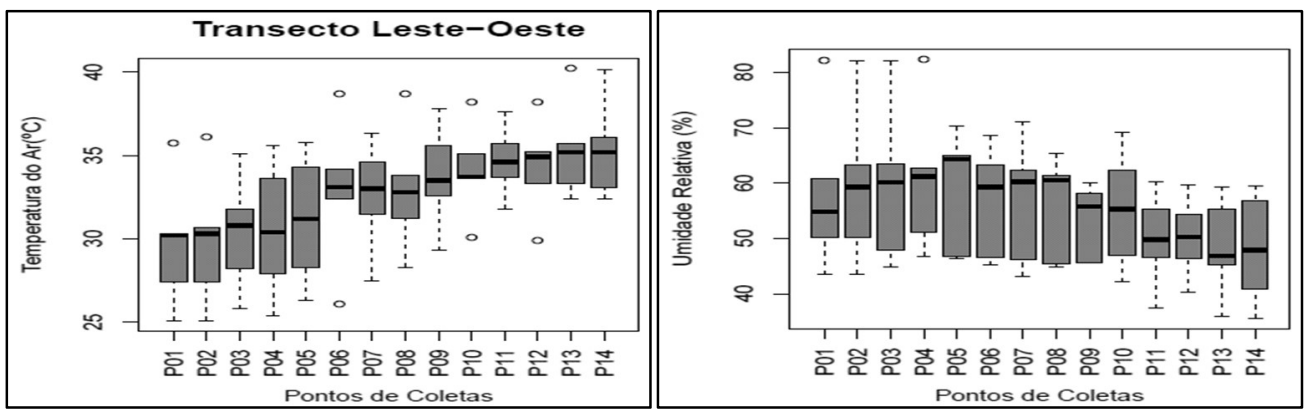

Figura 7: Temperatura e umidade relativa do ar nos diferentes pontos no transecto Leste-Oeste (Santarém - Alter do Chão).

A variação da temperatura e umidade ocorreu para o transecto Leste-Oeste apresentando um aumento na temperatura e flutuação nos valores de umidade relativa do ar, com variação significativa da temperatura do ponto um (P01) 27,5 a $30,3^{\circ} \mathrm{C}$ ao ponto quatorze (P14) com variação de 32,8 a $35,5^{\circ} \mathrm{C}$. É possível identificar dois pontos que apresentaram maiores diferenças, o ponto cinco (P05) que variou de 28,3 
a $35,5^{\circ} \mathrm{C}$ e o ponto nove (P09) que variou de $29,3^{\circ} \mathrm{C}$ a $37,8^{\circ} \mathrm{C}$. Os valores de umidade relativa do ar oscilaram entre $80 \%$ nos pontos 01,02 e 03 (zona rural) e 35\% nos pontos 12,13 e 14 (zona urbana).

Os mapas das figuras 8 e 9 apresentam, respectivamente, as variações espaciais da temperatura e umidade, para o horário de $15 \mathrm{~h}$. Neste horário foram observados os maiores valores de temperatura e os menores valores de umidade relativa. Em relação a temperatura é notado um aumento de temperatura em direção a região urbana com maior concentração de prédios e pavimentação, chegando até $4^{\circ} \mathrm{C}$ a mais do em regiões menos construídas (figura 8). No mapa da umidade relativa do ar (figura 9), nota-se que os pontos do -transecto Norte-Sul apresentam valores mais elevados do que os pontos do transecto Leste-Oeste. No primeiro transecto os valores de UR variam entre $43 \%$ e 52 \% e no segundo a variação gira em torno de 30 \% e $43 \%$, em ambos os transectos os valores são considerados baixíssimos e preocupantes, no que se refere ao conforte térmico.

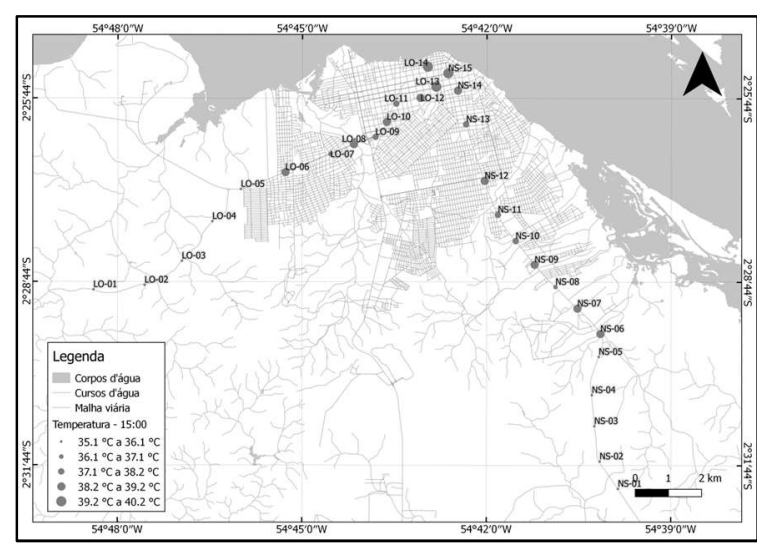

Figura 08. Variação espacial da temperatura ao longo dos pontos dos transectos Leste-Oeste (Santarém Alter do Chão) e Norte - Sul (Santarém-Curuá-Una) para o horário das $15 \mathrm{~h}$.

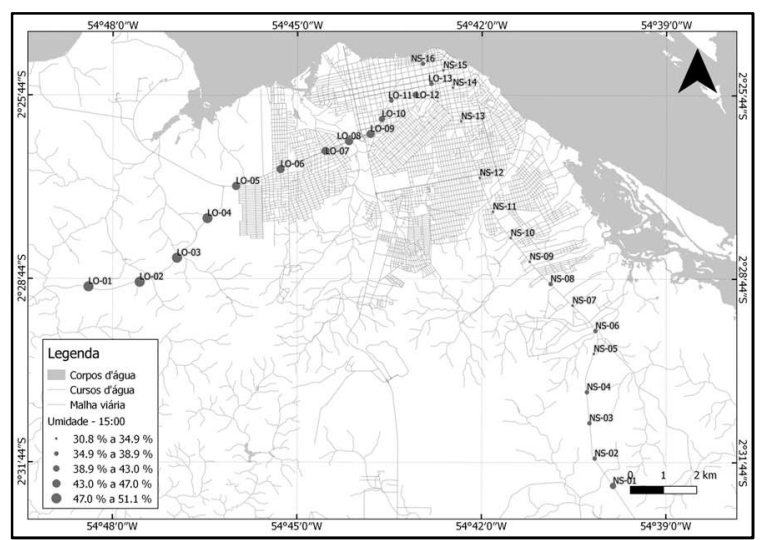

Figura 9: Variação espacial da umidade relativa do ar ao longo dos pontos dos transectos Leste-Oeste (Santarém - Alter do Chão) e Norte - Sul (Santarém-Curuá-Una) para o horário das $15 \mathrm{~h}$.

\section{Análise de variância}

A Variância apresentada pelos valores através do Teste de Tukey aplicado aos resultados da temperatura do ar e umidade do ar nos diferentes pontos levando em conta os dois transectos nos diferentes horários (figura 10). No transecto Norte - Sul a temperatura do ar apresentou similaridade nos horários de 9 , 12 e $18 \mathrm{~h}$, mas apresentou diferença para às $15 \mathrm{~h}$. Enquanto que às $15 \mathrm{~h}$ foi similar com as $12 \mathrm{~h}$, porém mostrou diferenças com $9 \mathrm{~h}$ e $21 \mathrm{~h}$, o horário das $18 \mathrm{~h}$ mostrou-se similar com o da $21 \mathrm{~h}$. No horário de $21 \mathrm{~h}$ foi observada a maior diferença com o horário das $15 \mathrm{~h}$.

Para o transecto Leste - Oeste maior diferença foi entre as médias de temperatura do ar registradas nos horários das $9 \mathrm{~h}$ às $15 \mathrm{~h}$ e das $15 \mathrm{~h}$ às $21 \mathrm{~h}$ mostrando uma amplitude maior em relação à comparação das outras médias temperatura do ar, contudo, existe diferenças entre 12 e 21h, com menor amplitude, o horário das $9 \mathrm{~h}$ mostrou similaridade com o das $21 \mathrm{~h}$, o horário das $12 \mathrm{~h}$ foi similar ao das $18 \mathrm{~h}$ e ao das $9 \mathrm{~h}$. Pelo teste de Tukey a análise da temperatura do ar ao nível de $5 \%$ mostra variação significativa para os dois transectos, sendo maior no transecto Leste - Oeste, o qual apresenta amplitude mais acentuada.

A análise feita para os pontos também mostrou diferença significativa pelo teste de Tukey a $95 \%$ de confiança, sendo pequena a diferença para os pontos analisados no transecto Norte-Sul, apresentando 
diferenças entre as médias de -6 para as menores temperaturas e 8 para as maiores temperaturas, já no transecto Leste Oeste a variação entre os pontos de coleta apresentou menor amplitude em relação à sua variação, sendo a amplitude máxima de 10. É possível inferir que a diferença pelo teste de comparação entre médias que a variação temporal é maior que a variação espacial para os dois transectos. Para a análise da umidade do ar nos dois transectos para os diferentes horários são apresentados os resultados na figura 11.
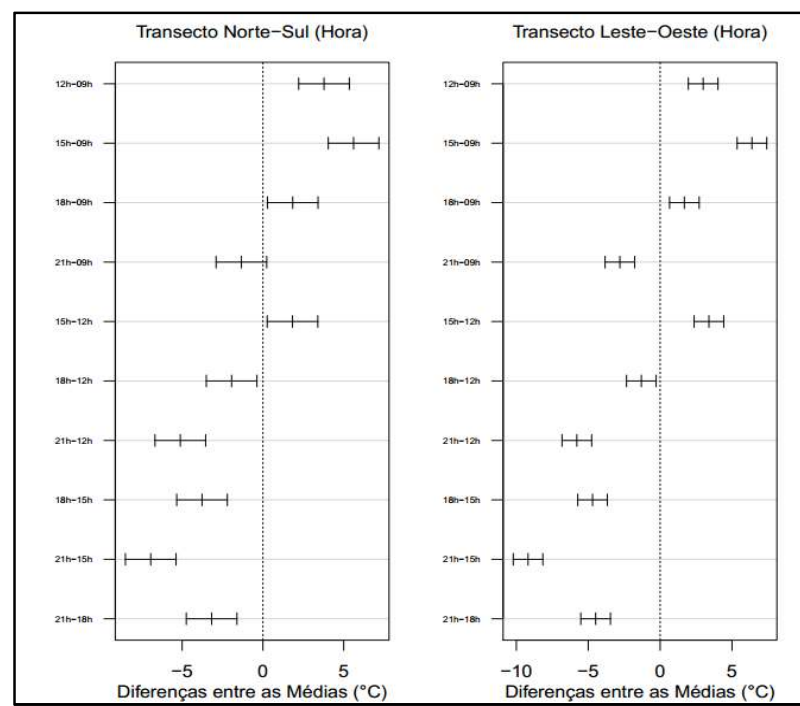

Figura 10: Variância da temperatura do ar para os transectos Leste-Oeste (Santarém - Alter do Chão) e

Norte - Sul (Santarém-Curuá-Una) em função do horário.

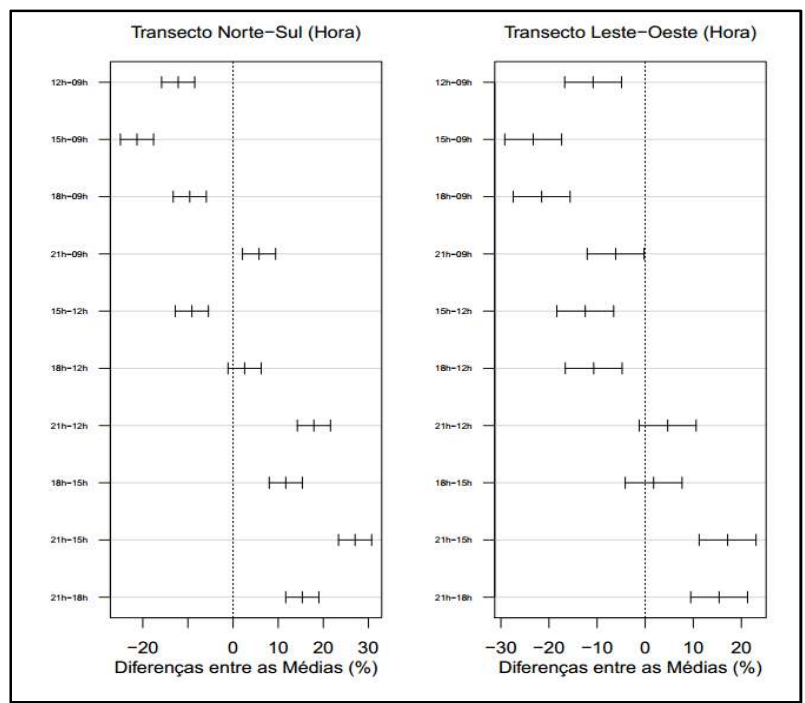

Figura 11: Diferença da Umidade do ar para os diferentes horários de coleta nos transectos Leste Oeste (Santarém - Alter do Chão) e Norte Sul (SantarémCuruá-Una).

A análise de variância também contemplou as médias de umidade do ar, sendo que as diferenças mais significativas foram encontradas para o transecto Leste Oeste, mostrando amplitude maior quando comparados os horários das $12 \mathrm{~h}$ e $15 \mathrm{~h}$, com os outros horários. No transecto Norte Sul a diferença entre a umidade nos horários de coleta mostrou-se similar à do transecto Leste oeste, pois a variação do horário mostrou-se influente para essa diferença, contudo esta ainda possui menor amplitude se comparada com o outro transecto. A análise de variância também foi aplicada para os valores de umidade em relação aos pontos de coletas, estas mostram uma diferença significativa, porém com um desvio menos se considerarmos as diferenças entre os horários, novamente os desvios apresentam-se maior para o transecto leste Oeste.

\section{Ilha de calor}

A formação da ilha de calor pode ser observada em todos os horários, sendo relacionadas as temperaturas dos pontos extremos dos dois transectos com a temperatura da área central da cidade (tabelas 3 e 4). A intensidade da ilha de calor no transecto Norte-Sul foi classificada como fraca nos horários de $18 \mathrm{~h}$ e 21h; fraca no horário de $12 \mathrm{~h}$ e forte nos horários de $9 \mathrm{~h}$ e $15 \mathrm{~h}$. No transecto Leste-Oeste, foram classificadas como forte no período de diurno no horário de $9 \mathrm{~h}, 12 \mathrm{~h}, 15 \mathrm{~h}, 18 \mathrm{~h}$ e muito forte no período noturno às $21 \mathrm{~h}$.

A formação das ilhas de calor nos dados do transecto Norte-Sul são de intensidade forte, moderada e fraca, devido as diferenças entre as temperaturas rural e urbana ser pequena, pois a variação verificada 
ficou entre 0,8 e $4,5^{\circ} \mathrm{C}$, isso significa que o centro da cidade em comparação à área rural da rodovia Santarém Curuá-Una apresenta temperaturas similares.

Para o transecto Leste-Oeste a intensidade da ilha de calor ficou entre forte e muito forte, isso se deve ao fato da temperatura da zona rural da rodovia Everaldo Martins ser menor que a zona urbana do centro da cidade, fazendo com que a diferenças dessas temperaturas sejam maiores se comparadas com as diferenças do transecto Norte Sul.

Tabela 3: Intensidade da ilha de calor no transecto Norte - Sul (Santarém-Curuá-Una).

\begin{tabular}{|c|c|c|c|c|}
\hline Hora & $\begin{array}{c}\text { Temperatura } \\
\text { Urbana }\left({ }^{\circ} \mathbf{C}\right)\end{array}$ & $\begin{array}{c}\text { Temperatura } \\
\text { Rural }\left({ }^{\circ} \mathbf{C}\right)\end{array}$ & Diferença $\left({ }^{\circ} \mathbf{C}\right)$ & Intensidade \\
\hline 9 & 35,5 & 31,0 & 4,5 & FORTE \\
\hline 12 & 36,5 & 33,5 & 3,0 & MODERADA \\
\hline 15 & 40,1 & 35,7 & 4,4 & FORTE \\
\hline 18 & 34,3 & 33,4 & 0,9 & FRACA \\
\hline 21 & 32,3 & 31,5 & 0,8 & \\
\hline
\end{tabular}

Tabela 4: Intensidade da ilha de calor no transecto Leste-Oeste (Santarém - Alter do Chão).

\begin{tabular}{|c|c|c|c|c|}
\hline Hora & $\begin{array}{c}\text { Temperatura } \\
\text { Urbana }\left({ }^{\circ} \mathrm{C}\right)\end{array}$ & $\begin{array}{c}\text { Temperatura } \\
\text { Rural }\left({ }^{\circ} \mathrm{C}\right)\end{array}$ & Diferença $\left({ }^{\circ} \mathrm{C}\right)$ & Intensidade \\
\hline $\mathbf{9}$ & 33,1 & 27,4 & 5,7 & FORTE \\
\hline $\mathbf{1 2}$ & 36,1 & 30,2 & 5,9 & FORTE \\
\hline $\mathbf{1 5}$ & 40,1 & 35,7 & 4,4 & FORTE \\
\hline $\mathbf{1 8}$ & 35,2 & 30,3 & 4,9 & FORTE \\
\hline $\mathbf{2 1}$ & 32,4 & 25,1 & 7,3 & MUITO FORTE \\
\hline
\end{tabular}

\section{Conforto térmico para os pontos dos dois transectos}

O índice de Temperatura e Umidade (ITU) para cada um dos pontos nos dois transectos indicou de maneira geral que a maioria dos pontos se apresentaram confortáveis na maior parte dos horários avaliados ao longo do dia, com exceção dos pontos P6, P9, P12 e P16 para o transecto Norte-Sul (Santarém-Curuá-Una) que se apresentaram na maior parte dos horários avaliados desconfortáveis (Tabela 05). Em relação ao transecto Leste-Oeste (Santarém - Alter do Chão) a maioria dos pontos se apresentaram desconfortáveis na maior parte dos horários avaliados ao longo do dia, com exceção dos pontos P1, P2 e P3 (tabela 5).

Tabela 5: Índice de conforto nos pontos do transecto Norte-Sul (Santarém-Curuá-Una).

\begin{tabular}{|c|c|c|c|c|}
\hline$P$ & TEMPERATURA MÉDIA $\left({ }^{\circ} \mathrm{C}\right)$ & UMIDADE MÉDIA (\%) & ITU $\left({ }^{\circ} \mathrm{C}\right)$ & $\begin{array}{c}\text { CONDIÇÃO DO CONFORTO } \\
\text { TÉRMICO }\end{array}$ \\
\hline 1 & 33,02 & 50,18 & 23,79 & Confortável \\
\hline 2 & 33,26 & 49,22 & 23,73 & Confortável \\
\hline 3 & 32,38 & 50,7 & 23,57 & Confortável \\
\hline 4 & 32,24 & 51,4 & 23,62 & Confortável \\
\hline 5 & 32,12 & 49,12 & 23,15 & Confortável \\
\hline 6 & 33,46 & 50,58 & 24,09 & Desconfortável \\
\hline 7 & 34,08 & 47,6 & 23,82 & Confortável \\
\hline 8 & 33,48 & 49,8 & 23,95 & Confortável \\
\hline 9 & 36,14 & 44,22 & 24,07 & Desconfortável \\
\hline 10 & 33,72 & 48,34 & 23,79 & Confortável \\
\hline 11 & 34,26 & 46,06 & 23,60 & Confortável \\
\hline 12 & 34,34 & 48,52 & 24,13 & Desconfortável \\
\hline 13 & 34,44 & 46,56 & 23,78 & Confortável \\
\hline 14 & 34,46 & 46,82 & 23,85 & Confortável \\
\hline 15 & 34,96 & 45,42 & 23,79 & Confortável \\
\hline 16 & 35,74 & 45,58 & 24,18 & Desconfortável \\
\hline
\end{tabular}


Tabela 6. Índice de conforto nos pontos do transecto Leste-Oeste (Santarém - Alter do Chão).

\begin{tabular}{|c|c|c|c|c|}
\hline $\mathrm{P}$ & TEMPERATURA MÉDIA $\left({ }^{\circ} \mathrm{C}\right)$ & UMIDADE MÉDIA (\%) & ITU $\left({ }^{\circ} \mathrm{C}\right)$ & $\begin{array}{c}\text { CONDIÇÃO DO CONFORTO } \\
\text { TÉRMICO }\end{array}$ \\
\hline $\mathbf{1}$ & 29,74 & 58,28 & 23,38 & Confortável \\
\hline $\mathbf{2}$ & 29,92 & 59,68 & 23,70 & Confortável \\
\hline $\mathbf{3}$ & 30,34 & 59,66 & 23,95 & Confortável \\
\hline $\mathbf{4}$ & 30,58 & 60,82 & 24,28 & Desconfortável \\
\hline $\mathbf{5}$ & 31,18 & 58,54 & 24,26 & Desconfortável \\
\hline $\mathbf{6}$ & 32,9 & 56,56 & 24,91 & Desconfortável \\
\hline $\mathbf{7}$ & 32,58 & 56,58 & 24,73 & Desconfortável \\
\hline $\mathbf{8}$ & 32,96 & 55,46 & 24,74 & Desconfortável \\
\hline $\mathbf{9}$ & 33,76 & 53,10 & 24,73 & Desconfortável \\
\hline $\mathbf{1 0}$ & 34,16 & 55,16 & 25,34 & Desconfortável \\
\hline $\mathbf{1 1}$ & 34,68 & 49,88 & 24,57 & Desconfortável \\
\hline $\mathbf{1 2}$ & 34,3 & 50,18 & 24,44 & Desconfortável \\
\hline $\mathbf{1 3}$ & 35,36 & 48,52 & 24,62 & Desconfortável \\
\hline $\mathbf{1 4}$ & 35,38 & 48,14 & 24,55 & Desconfortável \\
\hline
\end{tabular}

\section{DISCUSSÃO}

Houve um aumento da temperatura e redução da umidade nas áreas centrais quando comparado com a periferia da cidade, em concordância com estudos de Gomes et I. (2013). Os dados de temperatura apresentam ciclo diurno definido em escala temporal, apresentando aumento das primeiras horas até o meio do dia e diminuição a partir da tarde, associando os dados dos transectos, apresentam variações distintas, pois quanto mais se aproxima da cidade maior o gradiente térmico, sendo que as ilhas de calor possuem maior expressão nas grandes cidades, em estudo realizado na cidade de São Paulo, Lombardo (1985) encontrou diferenças térmicas de até $10^{\circ} \mathrm{C}$ no interior da cidade. Os valores de temperatura estão de acordo os resultados de Amorim (2005), que evidenciou em Birigui um perfil térmico com picos positivos de temperaturas nas áreas mais centrais da cidade.

Os maiores valores de umidade foram registrados no transecto Leste-Oeste (Santarém - Alter do Chão). Em estudo realizado em Santarém, Costa et al. (2013) encontrou que a estrutura termo-higrométrica apresentou variabilidade horária e diária nos diferentes locais estudados, e a temperatura do ar apresenta valor mais elevado no ambiente urbano, é possível afirmar que a diferença entre os valores de temperatura e umidade é mais acentuada em escala temporal do que em espacial, favorecendo o gradiente termohigrométrico na cidade. Assim, o padrão encontrado evidencia que no trecho analisado de Santarém já configura variação termo-higrométrica de centros urbanos, mesmo tendo proximidade com rios, igarapés e florestas.

Os maiores valores do índice de Temperatura e Umidade foram observados em direção ao centro da malha urbana, com destaque ao transecto Leste-Oeste (Santarém - Curuá-Una) que apresentou a partir de um ponto um gradiente de maiores valores, em direção ao centro urbano. Recentemente nestes pontos, dois novos aglomerados populacionais surgiram: o Residencial Salvação, do programa Minha Casa Minha Vida do governo federal, com 3.081 unidades e em torno de 15 mil pessoas, e a invasão Vista Alegre do Juá, atualmente com cerca 2.000 famílias. Na mesma área, o loteamento 'Cidade Jardim', com previsão de 5.225 lotes, desmatou cerca de 100 ha e atualmente é alvo de ação do Ministério Público do Estado do Pará - MPPA e Ministério Público Federal - MPF devido a irregularidades no licenciamento ambiental. A ocupação das 
áreas elencadas impacta diretamente o lago do Juá, que recebe toda a drenagem da microbacia do Juá/São Braz.

Os maiores valores do Índice de Temperatura e Umidade foram observados no centro da malha urbana de para Macapá (AP) (SILVA, 2016). As diferentes condições do Conforto Térmico ao longo dos dois transectos estão relacionados com as diferentes formas de absorção de calor dos materiais, com a emissão de calor antropogênico, a taxa de evaporação da água e a falta de áreas verdes no perímetro urbano da cidade, de acordo com Oliveira et al. (2010), sobre o sombreamento arbóreo na cidade de Cuiabá (MT), concluíram que a presença de vegetação contribui para uma sensação de conforto térmico fosse ideal para a população.

Esse contraste da área vegetada com a área onde apresenta um índice de urbanização mais elevado está relacionado com a absorção e dissipação de calor que é absorvido pelas diferentes superfícies dos materiais, resultado concordante com Costa et al. (2013), que encontrou menores temperaturas na área rural de Santarém em comparação com bairros mais urbanizados.

A variação ocorrida, nos dois transectos, mostra a relação do passar das horas com a variação de temperatura e umidade relativa do ar. Porém, no transecto Norte-Sul (Santarém-Curuá-Una) foram registrados os maiores valores de temperatura e menores valores de umidade em todos os horários das medições. Souza et al. (2014) verificou que o ambiente urbano da cidade de Manaus (AM) cria um aumento local na temperatura e uma diminuição da umidade relativa. A média anual observada chegou a apresentar diferenças de temperaturas em torno de $3^{\circ} \mathrm{C}$ e umidade relativa perto de $1,7 \%$.

A maior intensidade da llha de Calor Urbana ocorreu às 9h e 15h no transecto Norte-Sul (SantarémCuruá-Una), com diferenças de temperatura até $4,5^{\circ} \mathrm{C}$. A llha de Calor Urbana de Manaus, observada pelos autores, apresentou maior intensidade, um às $8 \mathrm{~h}$ local e outro entre $15 \mathrm{~h}$ e 17h locais (SOUZA et al., 2014). Também verificaram que a área urbana tende a perder calor antes e mais lentamente e esfriar mais tarde e mais rápido do que a floresta. Assim, como Oliveira (2009), que em seu estudo na cidade de Cascavel (PR) concluiu que diferença de radiação solar, assim como a diferença topográfica está relacionada com a diferença de temperatura e umidade.

Rocha e Fialho identificaram, no município de Viçosa (MG), variações de temperatura e umidade em dezembro de 2006 similares às encontradas no atual estudo, com temperatura e umidade inversamente proporcionais. Resultados de Leal (2012) relacionam os diferentes valores de temperatura e umidade ao longo do transecto urbano Leste - Oeste em Curitiba (PR), com a emissão de calor antropogênico, como o uso do solo, circulação de veículos e fatores ambientais como altitude do terreno e cobertura vegetal.

A região de expansão da malha urbana na região de Santarém-Curuá-Una, mostrou-se com menores amplitudes de temperatura entre a região urbana e rural. Isto pode estar relacionado que com o avanço da malha de expansão urbana ser mais antiga, junto com a implantação da hidrelétrica de Curuá-Una em 1977 (OLIVEIRA, 2008). O gradiente térmico se torna mais homogêneo, ou seja, a área rural está com temperatura mais próxima da encontrada na área urbana, configurando-se um gradiente com menor variação. Silva (2016) em estudo realizado sobre o clima urbano em Macapá (AP) verificou a formação de Ilha de Calor Urbana, 
aumenta à medida que se afastam do centro (malha urbana), com exceção, de lugares com vegetação (áreas verdes), que apresentam valores semelhantes ao das regiões periféricas.

Na região de Santarém-Alter do Chão a temperatura da área rural foi menor comparada a urbana, que resulta em Ilha de Calor Urbana, com intensidade forte (9h, 12h, 15h, 18h) e muito forte as $21 \mathrm{~h}$. Comparando os resultados de Silva (2016) indicam semelhança aos deste estudo, pois a llha de Calor Urbana é mais intensa durante a madrugada no período seco (outubro).

Isso implica em uma maior atenção de políticas públicas voltadas para esta área, visto que na Minuta do Projeto de Lei de Revisão do Plano Diretor de Santarém (2017) esta área é de expansão urbana. Neste sentido, por exemplo, sejam inseridas políticas públicas de arborização e que as licenças para novos loteamentos e ordenamentos insiram áreas verdes em seus projetos, assim como políticas voltadas a manutenção e remediação das áreas de proteção permanente ao longo dos igarapés e lagos inseridos nesta área. Há grandes chances da intensidade da llha de Calor Urbana aumentar e impactar substancialmente o conforto ambiental da população. Assim, estudos como este, como o diagnóstico do processo de formação e localização de Ilha de Calor Urbana fornecem subsídios ao planejamento urbano, bem como pode auxiliar no desenvolvimento de políticas públicas que resultem em melhoria da qualidade de vida dos habitantes (SILVA, 2016).

\section{CONCLUSÃO}

Chegou-se as seguintes conclusões, em relação ao efeito da expansão da malha urbana no transecto Norte-Sul (Santarém - Curuá-Una) e no transecto Leste-Oeste (Santarém-Alter do Chão) e seus efeitos no microclima e na formação/intensificação de Ilha de Calor Urbana e impactos no conforto ambiental da população. A variação temperatura e umidade relativa do ar na cidade de Santarém varia no sentido espacial, aumentando da área rural até a área urbana, a variação também ocorre com o passar das horas durante o dia, com destaque para o horário das $15 \mathrm{~h}$ que apresentou os maiores valores de temperatura do ar de $40,1^{\circ} \mathrm{C}$.

O estudo também mostrou maiores valores de temperatura e Sensação térmica em pontos específicos do transecto Leste-Oeste (Santarém-Alter do Chão), destaque para os pontos em frente ao loteamento 'Cidade Jardim', Residencial Salvação e a invasão Vista Alegre do Juá. Podendo estar relacionado com altitude mais baixa e mudança de uso do solo, estes pontos podem ser investigados posteriormente, pois a existência de áreas como vales e que foram desmatadas no processo de urbanização, precisam ser melhor compreendidas através de estudo de conforto térmico.

A Ilha de Calor é favorecida nos horários de menor incidência da radiação solar, o que permite o resfriamento do ambiente rural e a emissão de calor do centro urbano retida durante o dia. Estudos dessa natureza devem ser realizados com frequência para criar meios de mitigar problemas socioambientais relacionados com o desenvolvimento da cidade.

\section{REFERÊNCIAS}


AMORIM, M. C. C. T.. Ilhas de Calor em Birigui/SP. Revista Brasileira de Climatologia, v.1, n.1, 2005.

ARAUJO, A. P.; ALEIXO, N. C. R.; MENEZES, B. B.; SOUZA, C. G.; RIVERO, C. A. V.; MONTEZANI, E.; BRAIDO, L. M. H.; TEODORO, P. H. M.; AMORIM, M. C. C. T.. Ensaio metodológico sobre a utilização de transectos móveis no período diurno em Presidente Prudente-SP. Revista formação, n.17, v.1, p.77-95, 2010.

ARYA, S. P.. Introduction to Micrometeorology. 2 ed. California: Academic Press, 2001.

BARBOSA, P. H. D.; COSTA, A. C. L.; CUNHA, A. C.; QUADROS JUNIOR, J. D. A. S.. Variabilidade de elementos meteorológicos e de conforto térmico em diferentes ambientes na Amazônia Brasileira. Revista Brasileira de Climatologia, n.17, v.2, 2015.

BARBOSA, P. H. D.; COSTA, A. C. L.; CUNHA, A. C.; SILVA JÚNIOR, J. A.. Variabilidade de elementos meteorológicos e de conforto térmico em diferentes ambientes na Amazônia Brasileira. Revista Brasileira de Climatologia, v.17, n.1, p.98118, 2015.

COSTA, A. C. L.; SILVA JÚNIOR, J. A.; CUNHA, A. C.; FEITOSA, J. R. P.; PORTELA, B. T. T.; SILVA, G. G. C.; COSTA, R. F.. Índices de conforto térmico e suas variações sazonais em cidades de diferentes dimensões na Região Amazônica. Revista Brasileira de Geografia Física, v.6, n.3, p.478-487, 2013.

COSTA, A. C.; RODRIGUES, H. J. B; COSTA, J. L. O.; SOUZA, P. F. S.; SILVA JÚNIOR, J. A.; FEITOSA, A. C. L.. Variações termohigrométricas e estudo de llha de Calor Urbana na cidade de Bragança-PA e circunvizinhança. Revista Brasileira de Geografia Física. v.9, n.2, p.571-584, 2016.

DINIZ JÚNIOR, J.; COSTA, A. C. L.; SANTOS, M. R. P.; VIEIRA, L. C. R.; OLIVEIRA, A. A. R.; OLIVEIRA, L. L.. Influência da vegetação nos parâmetros micrometeorológicos da área urbana em uma cidade de médio porte da Amazônia. Ciência e Natura, p.264-267, 2013.

DUARTE, D. H. S.; SERRA, G. G.. Padrões de ocupação do solo e microclimas urbanos na região de clima tropical continental brasileira: correlações e proposta de um indicador. Ambiente Construído, v.3, n.2 p.7-20, 2003.

FIALHO, E. S., CELESTINO, E. J.; QUINA, R. R.. O campo térmico em situação episódica de primavera em uma cidade de pequeno porte, na zona da mata mineira: Um estudo de caso em Cajuri-MG. Revista de Geografia, Recife, v.33, n.4, 2016.

FREITAS, T. P. F.. Aspectos do Clima Urbano de Palmas-TO no Episódio de Outono-Inverno. Caminhos de Geografia, v.17, n.59, 103-125, 2016.

FROTA, A. B.; SCHIFFER, S. L.. Manual de conforto térmico. 5 ed. São Paulo: Estúdio Nobel, 2001.

GARTLAND, L.. Ilhas de calor: Como mitigar zonas de calor em áreas urbanas. São Paulo: Oficina de textos, 2010.

GOMES, M. F.; QUEIRÓZ, D. R. E.. Análise das variações termo-higrométricas e de conforto térmico na cidade de
Birigui-SP: Subsídios ao planejamento ambiental urbano, Revista Geoambiente, n.21, 2013.

GÓMEZ, A. L.; GARCÍA, F. F.. La isla de calor en Madri: avance de un estudio de clima urbano. Estudios Geográficos, Madri, v.45, n.174, p.5-34, 1984.

KING, V, J.; DAVIS, C.. A case study of urban heat islands in the Carolinas. Environmental Hazards. v.7, n.4, p.353-359, 2011. DOI: http://doi.org/10.1016/j.envhaz.2007.09.005

LEAL, L.. A influência da vegetação no clima urbano da cidade de Curitiba - PR. Tese (Doutorado em Engenharia Florestal) - Universidade Federal do Paraná, Curitiba, 2012.

MEMON, R. A.; LEUNG, D. Y. C.; CHUNHO, L. A.. A review on the generation, determination and mitigation of Urban Heat Island. Journal of Environmental Sciences, v.20, n.1, p.120$128,2008$.

NECHET, D.; CUTRIM, E.; SOUZA, D. C.; SOUZA, P. F. S. Variação diurna de eventos de trovoadas em Santarém-PA. In: CONGRESSO BRASILEIRO DE METEOROLOGIA, 14. Anais. Florianópolis: 2006.

NOBREGA, R. S.; LEMOS, V. S.. O microclima e o desconforto térmico em ambientes abertos na cidade do Recife- PE. Revista de Geografia, Recife, v.28, n.1, 2011.

OKE, T. R.. The energetic basis of the urban heat island. Quarterly Journal of the Royal Meteorological Society, v.108, n.455, p.1-24. 1982.

OLIVEIRA, J. M. G. C.. Expansão urbana e periferização de Santarém - PA, Brasil: questões para o planejamento urbano. In: COLÓQUIO INTERNACIONAL DE GEOCRÍTICA, 10. Anais. Barcelona: UB, 2008.

OLIVEIRA, S.; ANDRADE, H.; VAZ, T.. The cooling effect of green spaces as a contribution to the mitigation of urban heat: A case study in Lisbon. Building and Environment, v.46, n.11, 2011.

RIZWAN, A. M.; LEUNG Y. D.; CHUNHO, L. I. U.. A review on the generation, determination and mitigation of Urban Heat Island. Journal of Environmental Sciences, v.20, n.1, p.120128, 2011.

SILVA JÚNIOR, J. A.. Estudo do Conforto Térmico e o Fenômeno da ilha de calor na cidade de Belém-PA durante o ano de 2010. In: SIMPÓSIO INTERNACIONAL DE CLIMATOLOGIA, 6. Anais. João Pessoa: 2011.

SILVA, A. P. N.. Ilha de calor urbana: diagnóstico e impactos no microclima da região metropolitana de Macapá, AP Tese (Doutorado) - Universidade Federal de Campina Grande, Campina Grande, 2016.

SOUSA, C.; OLIVEIRA, L. L.. Avaliação termo-higrométrica e do conforto térmico da cidade de Santarém-PA. In: SEMINÁRIO DE INICIAÇÃO CIENTÍFICA III SEMINÁRIO DE INICIAÇÃO EM DESENVOLVIMENTO TECNOLÓGICO E INOVAÇÃO IV SEMINÁRIO DE INICIAÇÃO CIENTÍFICA DO ENSINO, 6. Anais. Santarém: 2016.

SOUSA, D. M., NERY, J. T.. O Conforto térmico na perspectiva da Climatologia Geográfica. Geografia, Londrina, v.21, n.2, p.65-83, 2012. 
SOUZA, D. O.; ALVALÁ, R. C.. Observational evidence of the urban heat island of Manaus City, Brazil. Meteorological Applications, v.21, p.186-193, 2014.

http://doi.org/10.1002/met.1340

TEZA, C. T. V.; BATISTA, G. M. M.. Identificação do fenômeno ilhas urbanas de calor por meio de dados ASTER, ondemand08 - Kinetic Temperature (III): metrópoles brasileiras. In: SIMPÓSIO BRASILEIRO DE SENSORIAMENTO REMOTO, 12. Anais. Goiânia: INPE, 2005.

UCHÔA, P. W. S.. Estudo de variações termo-higrométricas de cidade equatorial devido ao processo de urbanização: o caso de Santarém-PA. Dissertação (Mestrado) - Universidade Federal do Oeste do Pará, Santarém, 2011.

A CBPC - Companhia Brasileira de Produção Científica (CNPJ: 11.221.422/0001-03) detém os direitos materiais desta publicação. Os direitos referem-se à publicação do trabalho em qualquer parte do mundo, incluindo os direitos às renovaç̃̃es, expansões e disseminações da contribuiç̃o, bem como outros direitos subsidiários. Todos os trabathos publicados eletronicamente poderão posteriormente ser publicados em coletâneas impressas sob coordenação da Sustenere Publishing, da Companhia Brasileira de Produção Científica e seus parceiros autorizados. Os (as) autores (as) preservam os direitos autorais, mas não têm permissão pab coordenação da Sustenere Publishing, da Companhia Brasileira de Produçăo Cientifica e seus pã 